\title{
Greenhouse Energy Consumption for Rose Production in Different Regions of Portugal: Importance of Set-Points Definition and Energy Used
}

\author{
F.J. Baptista ${ }^{a}$ \\ Universidade de Évora/ICAAM \\ Escola de Ciências e Tecnologia \\ Departamento de Engenharia Rural \\ Núcleo da Mitra, Apartado 94, 7002-554 Évora \\ Portugal \\ J.F. Meneses \\ Instituto Superior de Agronomia \\ Universidade Técnica de Lisboa \\ Centro de Estudos de Engenharia Rural \\ Tapada da Ajuda, 1399-017 Lisboa \\ Portugal
}

\author{
E. San Jose, A.C. Guimarães and \\ L.M. Navas \\ Universidad de Valladolid \\ Departamento de Ingeniería \\ Agrícola y Forestal \\ Avda. Madrid, 44, 34004 Palencia \\ Spain
}

Keywords: plastic greenhouse, climate simulator, heating costs, natural gas, diesel

\begin{abstract}
In this work results of an energy consumption study for rose production in multi-tunnel greenhouses, located in Porto (Pedras Rubras), Marinha Grande, Dois Portos, Zambujeira, Faro, Funchal and Ponta Delgada, are presented. The greenhouse considered with a surface area of about 1 ha had galvanised steel structure and was covered with three layer co-extruded plastic films. It was equipped with a hot water heating system, natural ventilation through lateral and roof openings, shadow screens and an evaporative cooling system. A Greenhouse Climate Simulator (GCS) was used to analyse the energetic behaviour in the different regions. The GCS used monthly mean data measured over several years for solar radiation, temperature, wind speed and relative humidity. A climate generator was used to obtain the mean hourly climate data of a typical day for each month and location. As inputs the GCS requires data related with greenhouse characteristics, environmental control equipments and crop. Simulation results show the hourly trend of climatic and technological variables, such as heating, cooling power, etc. For the energy balance a static complex model was used which is based on heat and mass transfer processes. The model considers the following components: heat gains due to the heating system, heat gains due to the solar radiation, heat transfer by convection and conduction through the cover, heat losses by evapotranspiration, heat losses due to the cooling system, heat intercepted by the shadow screen and heat transfer by natural ventilation. The results show the energy consumption due to the heating system in each of the studied locations, as well the heat dissipated by the cooling system during an average year. For this study, a heating period was considered and two temperature set-points were chosen. A brief economic analysis of energy management is also presented, considering location, temperature set-point and energy source, for year-round production of cut roses in Portugal.
\end{abstract}

\section{INTRODUCTION}

In Portugal, the production of cut roses in greenhouses as increased during the last years. In order to obtain high yields and good quality, air temperature should be kept in the range from 17 to $25^{\circ} \mathrm{C}$. At night, temperature should not fall below $15^{\circ} \mathrm{C}$ and during the day it should not exceed $25^{\circ} \mathrm{C}$ (GPPAA, 2003).

a fb@uevora.pt

Proc. XXVIII ${ }^{\text {th }}$ IHC - IS on Greenhouse 2010 and Soilless Cultivation

Ed.: N. Castilla

Acta Hort. 927, ISHS 2012 